\title{
Drug Candidates for Covid-19 Treatment in Brazil
}

Luciano Barreto Silva

Corresponding Author: Luciano Barreto Silva,

Received Date: July 02, 2021; Accepted Date: September 16, 2021; Published Date: September 23,2021

Citation: Luciano Barreto Silva. (2021) Drug Candidates for Covid-19 Treatment in Brazil. J. Clinical Cardiology and Cardiovascular Interventions, 4(16); DOI:10.31579/2641-0419/200

Copyright: (c) 2021 Luciano Barreto Silva, This is an open-access article distributed under the terms of the Creative Commons Attribution License, which permits unrestricted use, distribution, and reproduction in any medium, provided the original author and source are credited.

\begin{abstract}
Background: COVID-19 has emerged worldwide in less than 6 months, leaving millions of deaths behind. While scientist search for new drugs, an old arsenal has been proposed as a form of treatment.

Objective: This article was designed as a literature review, scrutinizing antiparasitic chloroquine, ivermectin, nitazoxanide; and also glucocorticoids, as candidates to be applied in patients with COVID-19 in some Brazilian hospitals.

Methodology: clinical evidence of COVID-infected patients and literature consultation have been accomplished for the construction of this article. On line searches and gray literature have also been consulted, whose database include PUBMED Central, BVS/BIREME, Web of Science, Science Direct, Higher Level Personnel Improvement Coordinator (CAPES), Periodic Door (Portal de Periódicos da CAPES, The Cochrane Library and PROSPERO).

Results: chloroquine, ivermectin and nitazoxanide do present antiviral characteristics to support their usage in phase 1 of COVID-19 symptoms. Glucocorticoids, especially methylprednisolone and dexamethasone, seem to be efficient in patients with pulmonary symptoms, such as those present in phase $2 \mathrm{~B}$ and 3 of the disease.

Conclusion: After analyzing the literature, antiparasitic agents constitute a promising approach for patients with

COVID-19. However, their usage seems to be efficient in the very beginning of the symptoms. Methylprednisolone

and dexamethasone are best indicated for hospitalized patients with pulmonary commitment.

Keywords: ivermectin; chloroquine; nitazoxanide; glucocorticoids; SARS virus; coronavirus infections
\end{abstract}

\section{Introduction}

Pandemics have long affected mankind throughout its existence. In the early history, 1918 influenza pandemic, an unusual deadly influenza, caused by H1N1 a virus, lasted from February 1918 to April 1920, it infected 500 million people in a time that had no existence of antivirus or antibiotics.

Severe acute respiratory illness (SARI) appeared in China in 2019. An unusual outbreaks caused by coronavirus. Globally, there have been more than globally, there have been more than 3.800 confirmed cases of deaths reported to the World Health Organization. The recent pandemic disease named Coronavirus Disease 2019 (COVID-19), a virotic infection caused by SARS-CoV-2, belonging to the betacoronavirus genus, shares $79 \%$ genetic similarity with SARS-CoV 1 (Coronaviridae Study Group of the International Committee on Taxonomy of Viruses). The outbreak started in China as well, at the end of 2019 in the city of Wuhan, and in less than 4 months infected almost all countries all over the world, showing an unprecedent situation.

Knowing of what was yet to come, the scientific community reunited to establish a clinical protocol that could slow down the transmission of the virus, until an effective vaccine could finally be obtained. In this urgent process, exchange of information from countries that have been previously tried new approached for the treatment is fundamental, to avoid the loss of precious time finding the best way to treat the patients, in order to decrease the death rate, saving lives. Three antiparasitic drugs have been tried in this pandemic scenery, with more or less controversy, to treat COVID-19; namely: chloroquine, ivermectin and nitazoxanide. Chloroquine undoubtfully is the most controversial one; more due to political interference than to the probability of heart failures caused prolonged QT ECG wave.

The aim of this work was to describe the main drugs used in the treatment of COVID-19, based on the clinical evidence in Brazil, adopting the Spanish protocol in the three phases of the disease, based on clinical evidence.

COVID-19 classification by public and private hospitals from Recife Hospitals from Recife were some of the first hospitals to accept and treat patients with COVID-19 diagnosis.

With so many victims being handled every day, a protocol began to be adopted, based on the Spanish experience which used chloroquine in the 
initial symptoms of the disease, and pulse therapy corticoid for hospitalized patients. It is important to remind that such protocols are adopted using exclusively clinical evidence that had already been learned for the treatment of other diseases, and had been chosen because of their effect on the human organism had already been learned in previous situations. However, with the World Health Organization constant change of protocols, including having removed chloroquine under the argument that there was no real evidence of its security for COVID-19 patients, some hospitals removed it from their drug arsenal; even having had excellent experiences with it. As chloroquine has recently been accepted for further researches, the knowledge obtained from it, associated with ivermectin and nitazoxanide, and also corticoids, is now written in this article. The protocol classifies the disease in three different stages, as the following:

Stage 1- Viral replication stage. Symptoms concerning digestive system such as nausea, vomiting, diarrhea; and slight respiratory symptom such as coryza, anosmia, tiredness, malaise, fever and sore throat.

Stage 2: Inflammation phase. This stage is subdivided in two phases:

Phase 2A: Small viral replication. Inflammation trigged in more or less between the fifth and the seventh day after initial infection. Some degree of pulmonary infection is present, but without hypoxia. The big majority of the patients who look for medical assistance are categorized in this phase. Unspecific symptoms like cough, fever, headache, and diarrhea are present but the saturation levels continue in normal levels of $98 \%$. If a tomography is taken, the classical ground-glass image will be present, compromising nearly $30 \%$ of the lungs. D-dimer examinations and PCR levels will be altered as well.

Phase $2 \boldsymbol{B}$. Generally, this phase is reached around the tenth day of infection, and its main characteristics is lung commitment, showing a gradual decrease of saturation, and breathing difficulty. Gastrointestinal symptoms tend not to be present.

Stage 3 - Life threatening organic stress. Complications are systemic and serious, due to cytokine storm caused by pulmonary commitment. Mortality rate is high, reaching the levels of $80 \%$ to $90 \%$. Intravascular coagulation will be disseminated, that is, the formation of clots throughout the blood vessels which may bring as a result, thrombi formation that may cause vascular brain accidents or heart failure. The patients in this condition will certainly need intubation, and will be prone to develop secondary infections.

\section{Literature Review of COVID-19 Pandemic}

Emerging pandemics are also a challenge to scientists. The main question is always the same: what is causing the infection and how it is supposed to be treated. By facing the huge challenge of choosing which drug may be of first choice, it is necessary to take the decision based on clinical evidence acquired in routine treatments, by exchanging precious information with the scientific community scattered all over the world who have has been fighting the illness. Surprisingly as it may seem, old drugs used for decades, virtually forgotten for new researches, have now brought light to one of the most difficult times of modern world, faced before only by the end of World War II, during the Spanish flu pandemic.
From this point of view, The drugs below have been tried with promising results for the treatment of COVID-19. Apart from political points of view, all the information offered by this article have been collected from books and articles in order to give the reader impartial information about this matter.

\section{Hydroxychloroquine}

Chloroquine has been known in the medical community for a real long time. It was firstly reported in 1937; however, literature concerning its usage come from long before, more specifically from the time when Spain invaded South America, establising the trade with Europe. During that time, a plant named Chincona officinalis, used mainly for making teas to combat fever in the 17th century, originated the history of chloroquine in Europe (Fern, 2020). The newly presented drug in that time was named quinine, isolated in 1820; the predecessor of chloroquine.

Chloroquine itself was officially discovered in 1934 during the rise of Nazism in the second world war II; with the commercial name of Resochin, developed by Beyer laboratories (Krafts, 2012), in order to treat soldiers victims of malaria in the north of Africa mainly. It remained virtually ignored for a decade, as it was considered by some researchers to be too toxic for use in humans, due to its long term treatment for malaria. With the end of the world war II, the USA government studied the drug and improved it for military purposes, due to its being already well described with protocols by the Germans; and since then chloroquine became almost exclusively used for malaria and rheumatoid arthritis. With the brand-new outbreak of COVID-19, the 2020 pandemic, which is ongoing during the very construction of this paper, this old drug has been indicated for the treatment of the disease, with controversial results. As the pandemic went on, it has officially become a candidate for the first official form of treatment indicated by some countries, including Brazil, France and the USA.

Chloroquine is part of a large series of 4-amino-quinolines that have been thoroughly studied in the vast interwestern antimalarial research program conducted by the United States (Wallace, 1994). Although 4aminoquinolins had been previously described as potential antimalarials by Russian researchers, no greater attention was paid to this chemical group; until French researchers reported that 3-methyl-7-chlorine-4 (4diethylamino-1-methylbutylamino) quinoline (Fern, 2020) was well tolerated and had great activity in human malaria (Peters, 1970). Hence, in 1943, thousands of these compounds were synthesized and tested for malaria activity in birds and toxicity in mammals. From this series, ten of them were then studied in human volunteers with experimentally induced malaria. From these, chloroquine has been shown to be the most promising drug and has been released for clinical trials. When the war ended, it was discovered that the substance had been synthesized and studied by the Germans since 1934, under the name RESOCHIN, being presented as diphosphate in the form of white powder, bitter, soluble in water. Their solutions, however, were considered stable (Rockwell, 1978).

Although chloroquine has been developed primarily as an antimalarial drug, it has other pharmacological properties. Its use in the treatment of amoebiasis was satisfactory (Powell, 1971). Due to its anti-inflammatory properties, it has also been used in the treatment of discoid and systemic lupus erythematous (Rainsford, 2015); its effectiveness for this indication however, is still controversial (Dubois, 1978). 
The reason for the rediscovery of chloroquine in recent times reemerged during the epidemy of severe acute respiratory syndrome (SARS) caused by SARS coronavirus 1 , the previous member of the vast family Coronoviridae. SARS responded well to the treatment with hydroxychloroquine. Some countries, due to the rise of the pandemic and the thousands of dead patients, especially in Italy, have authorized its prescription in clinical trials, and so have Brazil and the USA. More recently yet, in the south-east of Brazil, São Paulo, the epicenter of the COVID-19 pandemic, studies are being carried out with a larger number of patients with the intention of establishing a protocol for the usage of hydroxychloroquine in the beginning of the symptoms, during the replication phase of the virus. Researchers claim that the ability of hydroxychloroquine in jeopardizing virotic entrance into the cytoplasm, by decreasing and disarranging ribosome activity to cleave the genetic material of the virus, should be better thought to be used while the systemic and more serious symptoms are not present, allowing patients to begin the treatment at home (Smith, 2020). For COVID-19 treatment, $400 \mathrm{mg}$ of hydroxychloroquine is used for a period that ranges from 5 to 7 days, in stage 1 , frequently associated with azithromycin.

Hydroxychloroquine differs from chloroquine because of the presence of a hydroxyl group, located at the end of the side chain, the $\mathrm{N}$-ethyl substituent is $\beta$-hydroxylated; forming a molecule that is available for oral administration in the form of hydroxychloroquine sulfate. Like chloroquine, it has a broad-spectrum against a wide range of fungal, bacterial and viral infections. Since chloroquine has been used for a considerable length of time, with acceptable tolerability and rare toxicity reports, associated to the fact that it is almost inexpensive with immunomodulatory features, it has been used in viral infections, such as immunodeficiency virus (HIV), as well as other viruses, due to its being efficient in jeopardizing virotic replication cycle (Savarino, 2003).

When chloroquine was administered in SARS-CoV-1, a dramatic dosedependent decrease in the number of virus antigen-positive was observed. So significant was the result, that $0.1-1 \mu \mathrm{M}$ chloroquine reduced the infection by nearly $50 \%$; and up to $90-94 \%$ inhibition was observed with 33-100 $\mu \mathrm{M}$ concentrations. With these results, some authors hypothesized that, as chloroquine was a lisosomotropic agent, another common lysosomotropic agent, $\mathrm{NH}_{4} \mathrm{Cl}$, also known as ammonium chloride, when associated with it might lead to better results. $\mathrm{NH}_{4} \mathrm{Cl}$ has been reported as being able to reduce pseudotypes viruses decorated with SARS-CoV spike protein (Simmons, 2004). Controversial as it is, the fact is that some drugs are being tested, alone or in combinations with chloroquine. A resume for the chloroquine quest are the following (Smith, 2020):

- Chloroquine - Limited in vitro clinical data and trials suggest a potential benefit when used alone.

- Hydroxychloroquine - In vitro and limited clinical data accomplished with low numbers of patients do suggest potential benefit.

- Azithromycin - Has been associated with hydroxychloroquine and are now being tested in COVID-19 therapy with positive results. Its use as adjunct therapy has brought hope for the treatment.

- $\mathrm{NH}_{4} \mathrm{Cl}$ (ammonium chloride).

\section{Ivermectin}

Ivermectin is a semisynthetic antiparasitic drug belonging to the avermectin class. It is composed of 22,23-dihydro-avermectin B1a (at least $90 \%$ ) and 22,23-dihydro-avermectin B1b (less than 10\%). It was discovered in 1975, and was officially presented to the medical community in 1981 as a relatively cheap drug, whose cost in the developing world for tablets was about US $\$ 0.12$ for a course of treatment, making it extremely available for nearly the whole world.

Avermectins are produced by fermentation of Streptomyces avermitilis. (Ref 1). It is used for parasite infestations caused by invertebrates, usually nematodes and insects, for both veterinary and human medicine (Burg, 1979). In invertebrate, Ivermectin binds selectively to glutamate-gated chloride ion channels in muscle and nerve cells, finally causing an increase in the permeability of the cell membrane to chloride ions. Such effect lead to the paralysis of the parasite, causing its death (Gisselmann, 2002).

In vertebrates, on the other hand, Ivermectin affects the central nervous system through reactions at the receptor for the gamma-aminobutyric acid (GABA) neurotransmitter, acting like a GABA receptor agonist Zheng (2002). As for humans, it is used in the treatment of parasitic infections, such as onchocerciasis or strongiloidasis. In some countries, more specifically under-developed ones, it has also been approved to be applied orally, for the treatment of scabies as well as for the topical treatment of head lice infestation. Due to these facts, it all indicates that global demand for this drug is expected to continue high, including the fact that ivermectin, when associated with albendazole and diethylcarbamazine (Thomsen, 2016), has excellent clinical responses with combined regimens for soil-trans mitted helminths, acting also as endoctocide by killing malaria vectors (Chaccour, 2013).

Nevertheless, there have been reports of toxic neurological effects related to high doses of ivermectin. Some of this adverse events have been initially reported in Africa, in the course of public health programs established by the government in order to eliminate onchocerciasis through community-based ivermectin treatment. The reports include cases of encephalopathy and coma, in patients with concomitantly high densities of filarial species, Loa loa. (Boussinesq 2003; Gardon 1997).

In spite of having been initially used as antiparasitic medication, antiviral activity has also been noticed. As for what concerns antiviral activity, Ivermectin was originally identified as an inhibitor of interaction between the human immunodeficiency virus-1 (HIV-1) integrase protein (IN) and the importin (IMP) $\alpha / \beta 1$ heterodimer responsible for IN nuclear import (Wagstaff et al., 2011). As researches went on, Ivermectin was identified as a having potent antivirus actitivy. It has been demonstrated to significantly reduce infection by RNA viruses such as DENV 1-4 (Tay et al., 2013), influenza virus (Gotz et al., 2016); West Nile Virus (Yang et al., 2020) and Venezuelan equine encephalitis virus (VEEV). Contrary to what was expected, no antivirus activity was found against ZIKA virus in mice (Ketkar et al., 2019). With so many antiviral activity documented, it was only natural to expect that Ivermectin was also capable of having some sort of activity over SARS-CoV2, the causative agent of COVID19 pandemic. This novel coronavirus is a single stranded positive sense RNA virussimilarly related to severe acute respiratory syndrome coronavirus 1 (SARS-CoV1).

As the researches began, it was clear that Ivermectin was capable of altering the host cell metabolism, thus changing virus ability to replicate. In this sense SARS-CoV accessory protein ORF6 has been shown to antagonize the antiviral activity of the STAT1 transcription factor by 
sequestering IMP $\alpha / \beta 1$ on the rough ER/Golgi membrane (Frieman et al., 2007). Also, studies on SARS-CoV proteins have shown a potential role for IMP $\alpha / \beta 1$ during infection in signal-dependent nucleocytoplasmic shutting of the SARSCoV nucleocapsid protein (Rowland et al., 2005; Timani et al., 2005; Wulan et al., 2015), which may jeopardize cell division (Hiscox et al., 2001; Wurm et al., 2001). With all this information taken together, these studies suggest that ivermectin's nuclear transport inhibitory activity may be effective against SARS-CoV-2.

A study conducted with cell culture (Calva, 2020) infected Vero/hSLAM cells with SARS-CoV-2 isolate Australia/VIC01/ 2020 at an MOI of 0.1 for $2 \mathrm{~h}$, followed by the addition of $5 \mu \mathrm{M}$ ivermectin. Supernatant and cell pellets were harvested at days 0-3 and analysed by RT-PCR for the replication of SARS-CoV-2 RNA. At the initial 24 hours, they observed a significant $93 \%$ reduction in viral RNA present in the supernatant, indicating virions released, of the samples which had been treated with ivermectin, when compared to the traditional vehicle DMSO used in routine cell culture experiments. More interesting yet was the $99.8 \%$ reduction in cell-associated viral RNA (indicative of unreleased and unpackaged virions), observed with ivermectin treatment. After 48 hours, such effect increased to an $\sim 5000$-fold reduction of viral RNA in the ivermectin treated groups compared to control samples, confirming that ivermectin treatment resulted in effective loss of virtually all viral material by 48 hours of experiment. Coherent with this idea, no further reduction in viral RNA was observed at 72 hours. This experiment showed that ivermectin is effective against SARS-CoV2 in vitro.

\section{Nitazoxanide}

The emerging strains of influenza virus, and also the limitations of the drug arsenal available for the many sorts of such respiratory viruses, there is an urge for new substances that might be useful in epidemic or pandemic situations. New mechanisms of pharmacodynamics and pharmacokinetics with neuraminidase inhibitors are now, more than in any other time period in modern society, needed as countermeasures against influenza. In this sense, the repurposing nitazoxanide as a model of treatment addressed for many sorts of influenza may be considered as important. Nitazoxanide was first synthesized in the beginning of the seventies (Rossignol and Cavier, 1975), developed as oral antiparasitic drug with tropism against protozoan and helminthic infections. Whether in vivo or in vitro, experiments accomplished in mammals such as mice, cats, dogs and sheep showed outstanding results (Cavier and Rossignol). Antiparasitic row of medications usually englobe old substances with more than 30 years of use, especially in underdevelopment countries due to poverty and overpopulation. Nitazoxanide was not different. It was first developed as an antiparasitic agent that would primarily act on protozoan and helminthic infections with promising results both in vitro and in vivo (Euzeby et al.,1980). It was firstly experimented in humans in the 1970s for the treatment of intestinal cestods (Rossignol and Maisonneuve, 1984), and soon after used in cell culture assays against intracellular protozoan Cryptosporidium parvum (Li et al., 2003; Baishanbo et al., 2006). Nitazoxanide soon became vastly used in Latin American countries due to the high incidence of parasitic infections in Brazil and in the surrounding countries. With growing clinical observations, Tizoxanide, the main active metabolite, became useful for a wide range of anaerobic gram positive and negative bacteria, showing antibacterial indications (Pankuch and Appelbaum, 2006; Hecht et al., 2007; Finegold et al., 2009; Freeman et al., 2011). Later on, in 2009, it was also shown to be active even on replicating and non-replicating strains of Mycobacterium tuberculosis (Carvalho et al., 2009). Tizoxanide seems to selectively block the maturation of the viral hemagglutinin (HA) of the influenza virus, impairing the trafficking of this protein inside the plasma membrane of the host (Rossignol, 2009).

As for what concerns the replication of RNA and DNA viruses in cell culture essays, tizoxanide inhibits their replication, particularly for respiratory syncytial virus, rotavirus, parainfluenza, hepatitis $\mathrm{B}$ and $\mathrm{C}$, arboviruses such as dengue, yellow fever, immunodeficiency virus (HIV), Japanese encephalitis virus, and finally coronavirus. For the later, it has been demonstrated that tizoxanide inhibits the replication of canine coronavirus S-378; murine coronavirus, mouse hepatitis virus strain A59, and enteric coronavirus 4408 (HECoV-4408) (Cao, 2015)

Nitazoxanide in that moment had been indicated as antiparasitic, as well as antibiotic agent. It was only natural that it was investigated as for antiviral properties. In this sense, Tizoxanide was then shown to be able to inhibit the replication process of 16 strains of influenza, including A/H1N1, H3N2, H3N2v, H3N8, H5N9, H7N1, and one strain of influenza B. (Belardo et al., 2011; Sleeman et al., 2014; Gubareva et al., 2014). The basic mechanism that modulates inflammation as a whole, intensifying or lessening its effects in the mammal body is cytokine production. The cytokine family is vast, but the main substances are the Interleukins (IL), Interferon (IFN), Tumor Necrosis Factor (TNF), Coloning-stimulating Factor (CSF), Chemokines (CKs), and Growth Factor (GF) (Yashimura, 1987). In the case of virotic infections, IFN plays an important role in neutralizing virus by stimulating infected cells and surrounding ones to produce proteins that prevents virus replication within them. Nitazoxanide seems to potentiate IFN- $\alpha$ and IFN- $\beta$ production, also exhibiting in vitro activity against MERS-CoV, as well as other coronavirus (Rossignol, 2016). As it was not enough, nitazoxanide applied $600 \mathrm{mg}$ a day for 5 days has been proven to decrease symptom duration in acute influenza with minor side-effects (Haffizulla, 2014). If such posology is applied in combination with azithromycin, as suggested in COVID-19 protocol, a potential decrease in SARS CoV-2 mortality and morbidity may be expected.

\section{Glucocorticoids}

Steroids have played a relevant role in COVID-19 pandemic. The first of them was officially introduced as a form of treatment in may 2020; named methylprednisolone. Nevertheless, as exchange of knowledge increased throughout the world, in June of the same year, the old dexamethasone was pointed as responsible for saving one third of the patients in phase three of COVID-19. A brief resume must be given to understand the importance of this class of drugs.

The adrenal cortex synthesizes two classes of steroids namely: glucocorticoids and mineralocorticoids (Santulli, 2015). The way they are produce depends on complex enzymatic reactions modulated by cholesterol, which is a mandatory intermediate in the synthesis of corticosteroids. Although the adrenal cortex synthesizes cholesterol from acetate by processes similar to the liver, most of the cholesterol, around 60 to $80 \%$, used for corticosteroidogenesis comes from exogenous sources, both at rest and after adrenocorticotropic hormone (ACTH) administration (Jefferies, 2004). In the absence of the adenohypophysis, responsible for the stimulation of suprarenal glands, adrenal cortex would suffer atrophy and the cortisol and corticosterone secretion rates would be so drastically reduced that 
they would not respond to otherwise effective stimuli. The available ccholesterol is then converted enzymatically to 21 -carbon corticosteroids and weak 19-carbon androgens by reactions catalyzed by iso-functional oxidases that contain cytochrome P-450 and require NADPH and molecular oxygen (O'Hare, 1982)

The effects of corticosteroids are numerous and widespread. They have activities in many of the human systems, as well as in numbers of susceptible molecules. They influence, for instance, the metabolism of carbohydrates, lipids, and the electrolyte balance and the functions of the cardiovascular, renal, skeletal muscles, central nervous system, and other organs and tissues. In addition, corticosteroids give organisms the ability to withstand many types of harmful stimuli and environmental changes. The adrenal cortex is the organ, par excellence, of homeostasis, being responsible for the relative freedom that higher organisms exhibit in environments with constant changes. If the adrenal cortex did not exist, survival would be possible only under strictly restricted conditions. For instance, a given dose of corticosteroid may be pharmacological or physiological. Under favorable conditions, a small dose of corticosteroid keeps an adrenalectomized animal in a state of well-being. In adverse conditions, on the other hand, a relatively large dose would be necessary for the same animal to survive (Whitehead, 2001).

Cortisone was firstly isolated in 1953 , and soon after used in the treatment of acute rheumatoid arthritis. In the summer of 1954, the clinical application and the benefits of cortisone and adrenocorticotropic caused a revolution in the scientific world and in clinical practices all over the world. From that point on, corticoids have been vastly applied in virtually every branch of medicine (HENCH, 1949; HENCH, 1950).

With such revolutionary drugs, new modalities of treatment were implemented, and have been used since modern days, more specifically in the 2020 pandemic, for the clinical approach of COVID-19 infected patients. Corticosteroids belong to a class of chemicals that encompass both laboratory-synthesized substances and naturally produced hormones, representing a standard therapy for controlling inflammation for a number of diseases, such as asthma, wild ranges of allergy including anaphylaxis, vascular alterations, inflammatory bowel and other systemic situations, including otitis and ocular inflammatory diseases as well. This versatility is due to their anti-inflammatory associated with immunosuppressive actions, as well as inevitable and unwanted side effects as any other drug (Ericson-Neilsen, 2014; Van der Goes, 2014).

Among the negative effects of glucocorticoids, it is possible to mention avascular necrosis of the bone in patients with long-term treatment duration; although there have been reports of their happening in shorter time periods (WEINSTEIN, 2012). Osteoporosis has also been related in prolonged treatment duration (COSMAN, 2014); this was warned by the American College of Rheumatology, relating the risks to the use of steroids (AMERICAN COLLEGE OF RHEUMATOLOGY). Other less wanted side effects include myopathy (SCHAKMAN, 2008); weight gain and cushingoid features (Da Silva, 2006); cardiac side effects (McGavock, 2007; Van der Hooft, 2006; Souverein, 2004) such as hypertension (Huscher, 2009); Adrenal suppression (Aceto, 1966) through feedback mechanisms; dermatologic side effects, since corticosteroids seem to affect keratinocytes and prevent collagen secretion as well as hyaluronic acid by fibroblasts in dermis (Da Silva, 2006); neuropsychiatric side effects, such as mood changes, depression, euphoria, irritability, akathisia and anxiety (Brown, 2001), ophthalmologic side effects such as cataract (11-15\%) and glaucoma $(12.8 \%)$ whose risks increases with the amount of dose and the length of treatment (Fel, 2011; James, 2007);

The clinical approach of glucocorticoids offers a wide variety, appliable for different matters in the health area. In general, for oral use, prednisone, prednisolone, methylprednisolone, as well as dexamethasone are the most commonly used. However, clinical emergencies require a different protocol due to life threatening situations. Therefore, in face of severe or even uncontrolled disease, methylprednisolone is the most used steroid, often applied intravenously (IV), in what is defined as high dose pulsetherapy. This sort of therapy implies in doses equal or above $250 \mathrm{mg}$ which is gradually reduced depending on the situation (Czock, 2005). Once liberated in the circulation, glucocorticoids will exert their effects by finding their receptors located in the cell membranes, translocating to the nucleus and targets gene transcription (Tanaka, 1994). The efficacy of pulse-therapy is partially explained through nongenomic mechanisms, due to doses that are greater than the saturation dose for glucocorticoid receptor. In less urgent situations, glucocorticoids can be applied orally, and are well absorbed after administration. The problem is that absorption takes place irregularly from patient to patient, and therefore happens in variable degrees of their binding to globulin and albumin (Czock, 2005). Therefore, only intact free glucocorticoid can indeed interact with the glucocorticoid receptor; and that is exactly the main reason to justify pulse-glucocorticoid-therapy: urgency; the need of massive free drug to control the ongoing organic damage.

COVID-19 has caused a revolution in the medical science as researchers find new paths for healing. In this sense, information discovered in one week may became obsolete in the following, due to the great amount of researches being carried out. Therefore old dexamethasone has recently been demonstrated to be a lifesaving option in the management of hospitalized patients victims of COVID-19, being able to reduce mortality by one third of all the patients in the study (BMJ, 2020). All the evidence acquired in the UK experiment indicates that dexamethasone be indicated as a form of treatment for COVID-19 infection, converged especially for hospitalized patients and also for suspected, or confirmed patients, under oxygen therapy including non-invasive or invasive ventilation. As the experiment was carried out in adults, the likely evidence of the benefits in children remains unproven (BMJ, 2020). The dosage is one of the most important conclusions taken by the UK study concerning dexamethasone. For $2 \mathrm{mg}$ tablets, it is indicated a dosage three tablets once a day for 10 days. For dexamethasone $2 \mathrm{mg} / 5 \mathrm{~mL}$ oral solution, it is indicated a dosage of $15 \mathrm{~mL}$ once a day for 10 days. For dexamethasone $3.3 \mathrm{mg} / \mathrm{mL}$ intravenous $1 \mathrm{ml}$ ampoules: dosage $1.8 \mathrm{~mL}(5.94 \mathrm{mg})$ once a day for 10 days (BMJ, 2020). Table 1 explains the relative power and equivalent doses of corticosteroids. 


\begin{tabular}{|c|c|c|c|c|}
\hline Compound & $\begin{array}{c}\text { Relative anti- } \\
\text { inflammatory power }\end{array}$ & $\begin{array}{l}\text { Relative sodium } \\
\text { retention power }\end{array}$ & $\begin{array}{c}\text { Duration of } \\
\text { action* }\end{array}$ & $\begin{array}{c}\text { Approximate } \\
\text { equivalent } \\
\text { dose (mg) }\end{array}$ \\
\hline Cortisol (hydroxycortisone) & 1 & 1 & $\mathrm{C}$ & 20 \\
\hline Tetrahydrocortisol & 0 & 0 & $\ldots$ & $\ldots$ \\
\hline Prednisone & 4 & 0.8 & $\mathrm{I}$ & 5 \\
\hline Prednisolone ( $\Delta 1$-Cortisone $)$ & 4 & 0.8 & $\mathrm{I}$ & 5 \\
\hline $6 \alpha$-Methilprednisolone & 5 & 0.5 & $\mathrm{I}$ & 4 \\
\hline Fludrocortisone & 10 & 125 & $\mathrm{C}$ & $=$ \\
\hline 11-Dehydrocortisol & 0 & 0 & $\ldots$ & - \\
\hline Cortisone (11-Dehydrocortisol) & 0.8 & 0.8 & $\overline{\mathrm{C}}$ & $\overline{25}$ \\
\hline Corticosterone & 0.35 & 15 & $\mathrm{C}$ & $\ldots$ \\
\hline Triamcinolone & 5 & 0 & $\mathrm{I}$ & 4 \\
\hline Parametasone & 10 & 0 & $\mathrm{~L}$ & 2 \\
\hline Betamethasone & 25 & 0 & $\mathrm{~L}$ & 0.75 \\
\hline Dexamethasone & 25 & 0 & $\mathrm{~L}$ & 0.75 \\
\hline
\end{tabular}

$* \mathbf{C}=$ Short biological half-life or 8 to 12 hours. $\mathbf{I}=$ intermediate half-life or 12 to 36 hours; $\mathbf{L}=$ Long biological half-life, from 36 to 72 hours. This dose ratio applies only to intravenous or oral administration; the relative powers can differ greatly when injected via the muscle or joint spaces due to variables inherent in these pathways.

TABLE 1: Relative power and equivalent doses of corticosteroids

Judging from the data exposed on Table 1, it becomes easy to conclude the reason why dexamethasone has been successful in reducing death rates when applied in phase 3 pulmonary patients. It is powerful enough to exert its anti-inflammatory effects without retaining sodium, with a long half-life with low doses.

COVID-19 ongoing pandemic required fast and efficient clinical protocol which has not yet been established. However; growing clinical evidence has brought light to this matter, strongly indicating pulse-therapy for patients in the $2 \mathrm{~B}$ stage, due to the risk of pulmonary permanent demage. The use of corticoids has been modulating the course of the disease, reducing significantly the number of deaths all over the world.

\section{Final considerations}

Up to the construction of this article, the SARS CoV 2 pandemic is still ongoing, collapsing countries economically, politically and socially, due to the astonishing numbers of deaths left behind. It is not the first time that such a lethal pandemic spread so quickly throughout the world. The Spanish flu for instance, left an incredible number of estimated 500 million victims, and can not be compared to COVID-19 results, at least not until now. Therefore, scientists had nothing left to do but use what had previously been applied in epidemies that happened beforehand. In such scenery, contrary to what could be expected, drugs with more than thirty years of use have now reemerged, such as the ones reviewed in this article.

Controversy has caused the World Health Organization (WHO) to contraindicate the use of Hydroxychloroquine under the declaration that there was no scientific evidence that might indicate it for any phase of COVID-19. They added that Hydroxychloroquine might cause even more deaths due to QT prolongation in the ECG. Surprisingly as it may seem, azithromycin, which also causes QT prolongation, and that is often associated with hydroxychloroquine, had not been not mentioned as a potential hazard when associated with chloroquine (Mosholder, 2013). Nevertheless, in June 2020, WHO admitted errors in the methodology of the work intitled "Hydroxychloroquine or chloroquine with or without a macrolide for treatment of COVID-19: a multinational registry analysis" due to its having been accomplished in hospitalized patients (Mandeep, 2020), contrary to the main indication that it should be used in the beginning of the symptoms in countries like Spain, Brazil and the USA. In this situation, there are two drugs that may offer arrythmia risks when applied together, and therefore should be studied concomitantly in the initial days of COVID-19.

Time and researches are necessary to assess any drug effect on the human physiology. In this sense and orientation, no antiparasitic drugs can be indicated as the best form to combat coronaviruses, especially when most of them reflect in vitro studies. Glucocorticoids have now been comprehended as the best form to treat patients in phase $2 b$ and in phase 3 , due to pulmonary commitment. The contrary must be understood, simply because, if applied in the phase 1 during viral replication, corticosteroids may suppress immune defenses, fragilizing even more the infected host. Patients with hypoxia and pulmonary damages should use prednisone pulse therapy, with discontinuous intravenous infusion with more than $250 \mathrm{mg}$ prednisone or its equivalent per day, for one or more days. Therefore, care must be taken, associated with open mindedness.

\section{Conclusions}

There is no official treatment for COVID-19 up to the moment of the construction or these article. Due to the urge of an effective drug that may halt the pandemic, chloroquine, ivermectin and nitazoxanide seem to be promising according to clinical reports. Above them all, glucocorticoids have emerged as the best drug group able to offer a more secure and predictable outcome. Their indication, however, needs correct scientific investigation with proper methodology in a way that protects the patients while it is effective against COVID-19. Until then, however; their application must be used and planned carefully.

\section{REFERENCES}

1. Fern, Ken (2010-2020). "Cinchona officinalis - L." Plans for a Future. Archived from the original on 25 August 2017. Retrieved 2 February 2020. 
2. Krafts K, Hempelmann E, Skórska-Stania A (July 2012). "From methylene blue to chloroquine: a brief review of the development of an antimalarial therapy". Parasitology Research. 111 (1): 1-6.

3. Wallace DJ. Antimalarial agents and lupus. Rheum Dis Clin North Am. 1994;20(1): 243-63. Review.

4. Peters W. -Chemotherapy and drug resistance in malaria. Ipswich, Academic Press, 1970. 876 p.

5. Rockwell DA. Psychiatric complications with chloroquine and quinacrine. Am J Psychiatry. 1968;124(9):1257-1260.

6. Powell SJ: Therapy of amebiasis. Bull NY Acad Med 47:469477, 1971

7. Rainsford KD, Parke AL, Clifford-Rashotte M, Kean WF. Therapy and pharmacological properties of hydroxychloroquine and chloroquine in treatment of systemic lupus erythematosus, rheumatoid arthritis and related diseases. Inflammopharmacology. 2015;23(5):231-69.

8. Dubois EL. Antimalarials in the management of discoid and systemic lupus arythematosus. Semin Arthritis Rheum. 1978;8:33-51.

9. Smith T, Bushek J, Prosser T. COVID-19 Drug therapy Potential Options. Elsevier, March 26, 2020.

10. Savarino A, Boelaert JR, Cassone A, Majori G, Cauda R (November 2003). "Effects of chloroquine on viral infections: an old drug against today's diseases?". The Lancet. Infectious Diseases. 3 (11): 722-7.

11. Simmons G, Reeves JD, Rennekamp AJ, Amberg, SM, Piefer AJ. Bates P. Characterization of severe acute respiratory syndrome-associated coronavirus (SARS-CoV) spike glycoprotein-mediated viral entry. Proc Natl Acad Sci. usa 2004. 101 4240-4245.

12. Burg, R. W. et al. Avermectins, new family of potent anthelmintic agents: producing organism and fermentation. Antimicrob. Agents Ch. 15, 361-367 (1979).

13. Gisselmann G., Pusch H., Hovemann B. T., Hatt H. (2002) Two cDNAs coding for histamine-gated ion channels in $\mathrm{D}$. melanogaster. Nat. Neurosci. 5, 11-12 [PubMed] [Google Scholar]

14. Zheng Y., Hirschberg B., Yuan J., Wang A. P., Hunt D. C., Ludmerer S. W., Schmatz D. M., Cully D. F. (2002) Identification of two novel Drosophila melanogaster histamine-gated chloride channel subunits expressed in the eye. J. Biol. Chem. 277, 2000-2005 [PubMed] [Google Scholar]

15. Thomsen EK, Sanuku N, Baea M, et al. Efficacy, safety, and pharmacokinetics of coadministered diethylcarbamazine, albendazole, and ivermectin for treatment of bancroftian filariasis. Clin Infect Dis 2016; 62: 334-41.

16. Chaccour CJ, Kobylinski KC, Bassat Q, et al. Ivermectin to reduce malaria transmission: a research agenda for a promising new tool for elimination. Malar J 2013; 12: 153.

17. Boussinesq M, Gardon J, Gardon-Wendel N, Chippaux JP, 2003. Clinical picture, epidemiology, and outcome of Loaassociated serious adverse events related to mass ivermectin treatment of onchocerciasis in Cameroon. Filaria J 2 (Suppl 1): S4. [PMC free article] [PubMed] [Google Scholar]
18. Gardon J, Gardon-Wendel N, Demanga-Ngangue, Kamguo J, Chippaux JP, Boussinesq M, 1997. Serious reactions after mass treatment of onchocerciasis with ivermectin in an area endemic for Loa loa infections. Lancet 350: 18-22. [PubMed] [Google Scholar]

19. Wagstaff, K.M., et al., 2011. An AlphaScreen(R)-based assay for high-throughput screening for specific inhibitors of nuclear import. J. Biomol. Screen 16 (2), 192-200.

20. Tay, M.Y., et al., 2013. Nuclear localization of dengue virus (DENV) 1-4 non-structural protein 5; protection against all 4 DENV serotypes by the inhibitor Ivermectin. Antivir. Res. 99 (3), 301-306.

21. Gotz, V., et al., 2016. Influenza A viruses escape from MxA restriction at the expense of efficient nuclear vRNP import. Sci. Rep. 6, 23138.

22. Yang, S.N.Y., et al., 2020. The broad spectrum antiviral ivermectin targets the host nuclear transport importin alpha/beta1 heterodimer. Antivir. Res. 104760.

23. Ketkar, H., et al., 2019. Lack of efficacy of ivermectin for prevention of a lethal Zika virus infection in a murine system. Diagn. Microbiol. Infect. Dis. 95 (1), 38-40.

24. Frieman, M., et al., 2007. Severe acute respiratory syndrome coronavirus ORF6 antagonizes STAT1 function by sequestering nuclear import factors on the rough endoplasmic reticulum/Golgi membrane. J. Virol. 81 (18), 9812-9824.

25. Rowland, R.R., et al., 2005. Intracellular localization of the severe acute respiratory syndrome coronavirus nucleocapsid protein: absence of nucleolar accumulation during infection and after expression as a recombinant protein in vero cells. J. Virol. 79 (17), 11507-11512.

26. Timani, K.A., et al., 2005. Nuclear/nucleolar localization properties of C-terminal nucleocapsid protein of SARS coronavirus. Virus Res. 114 (1-2), 23-34.

27. Wulan, W.N., et al., 2015. Nucleocytoplasmic transport of nucleocapsid proteins of enveloped RNA viruses. Front. Microbiol. 6, 553.

28. Hiscox, J.A., et al., 2001. The coronavirus infectious bronchitis virus nucleoprotein localizes to the nucleolus. J. Virol. 75 (1), 506-512.

29. Wurm, T., et al., 2001. Localization to the nucleolus is a common feature of coronavirus nucleoproteins, and the protein may disrupt host cell division. J. Virol. 75 (19), 9345-9356.

30. Calya L, Drucea D. J, Cattona M, Jansb D, Wagstaffb KM. The FDA-approved drug ivermectin inhibits the replication of SARS-CoV-2 in vitro. Antivirus Research 178 (2020) 104787.

31. Rossignol J-F. Nitazoxanide, a new drug candidate for the treatment of Middle East respiratory syndrome coronavirus. Journal of Infection and Public Health. 2016;9(3):227-230. doi: 10.1016/j.jiph.2016.04.001. [PMC free article] [PubMed] [CrossRef] [Google Scholar].

32. Cavier, R., Rossignol, J.F., 1982. Etude de diverses associations d'anthelminthiques chez la souris. Rev. Méd. Vét. 133, 779783.

33. J. Euzeby, T.S. Prom, J.F. Rossignol. Experimentation des propriétés anthelminthiques de la nitazoxanide chez le chien, le 
chat et les ovins.Rev. Méd. Vét., 131 (1980), pp. 687-696.View Record in ScopusGoogle Scholar

34. J. Li, Z. Bao, D. Zhuang, S. Liu, Y. Liu, W. ZhangInactivation efficacy on new coronavirus of a compound disinfecting nanoemulsion Chin. J. Disinfection, 20 (2003), pp. 116-117 [in Chinese].

35. Baishanbo A, Gargala G, Duclos C, Françoes A, Rassignol JF, Ballet JJ, Favennec L (2006). Efficacy of nitazoxanide and paromomycin in biliary tract cryptosporidiosis in an immunosuppressed gerbil model. J. Antimicrobe Chemother 57(2); 353-355

36. Pankuch, G. A., and P. C. Appelbaum. 2006. Postantibiotic effect of ceftobiprole against 12 gram-positive organisms. Antimicrob. Agents Chemother. 50:3956-3958. [PMC free article] [PubMed] [Google Scholar]

37. Hecht DW, Galang MA, Sambol SP, Osmolski JR, Johnson $\mathrm{S}$, Gerding DN. In vitro activities of 15 antimicrobial agents against 110 toxigenic Clostridium difficile clinical isolates collected from 1983 to 2004, Antimicrob Agents Chemother, 2007, vol. 51 (pg. 2716-9)

38. Finegold, S.M., Molitoris, D., Vaisanen, M.L., 2009. Study of the in vitro activities of rifaximin and comparator agents against 536 anaerobic intestinal bacteria from the perspective of potential utility in pathology involving bowel flora. Antimicrob. Agents Chemother. 53, 281-286.

39. Freeman, J., Baines, S.D., Todhunter, S.L., Huscroft, G.S., Wilcox, M.H., 2011. Nitazoxanide is active against Clostridium difficile strains with reduced susceptibility to metronidazole. J. Antimicrob. Chemother. 66, 1407-1408

40. Carvalho, G. G. P. de; Pires, A. J. V. ; Garcia, R. ; Veloso, C. M. ; Silva, R. R. ; Mendes, F. B. L. ; Pinheiro, A. A. ; Souza, D. R. de, 2009. In situ degradability of dry matter, crude protein and fibrous fraction of concentrate and agroindustrial byproducts. Ciência Anim. Bras., 10 (3): 689-697

41. Rossignol JF, La Frazia S, Chiappa L, Ciucci A, Santoro MG. Thiazolides, a new class of anti-influenza molecules targeting viral hemagglutinin at the post-translational level. J Biol Chem 2009; 284:29798-808.

42. J. Cao, J.C. Forrest, X. ZhangA screen of the NIH collection small molecule library identifies potential coronavirus Antiviral Res, 114 (2015), pp. 1-10

43. Belardo, G., La Frazia, S., Cenciarelli, O., Carta, S., Rossignol, J.F., Santoro, M.G., 2011.

44. Sleeman, K., Tamura, D., Chesnokov, A., De La Cruz, J., Villaneuva, J., Davis, T., 2014. Susceptibility of avian influenza A(H7N9) viruses to FDA approved and investigational antiviral drugs. Programme \& Abstract Book, Influenza and Other Respiratory Virus Infections: Advances in Clinical Management. Third ISIRV-Antiviral Group Conference. Abstract P57, 83.

45. Gubareva, L.V., Marjuki, H., Mishin, V.P., Sleeman, K., Tamura, D., Chesnokov, A., De La Cruz, J., Villaneuva, J., Davis, T., 2014. Susceptibility of avian influenza A(H7N9) viruses to FDA approved and investigational antiviral drugs. Programme \& Abstract Book, Influenza and Other Respiratory
Virus Infections: Advances in Clinical Management. Third ISIRV-Antiviral Group Conference. Abstract P57, 83.

46. Yoshimura T, Matsushima K, Tanaka S. et al. Purification of a human monocyte-derived neutrophil chemotactic factor that has peptide sequence similarity to other host defense cytokines. Proc Natl Acad Sci USA 84:9233-9237. 1987.

47. Haffizulla J., Hartman A., Hoppers M. Effect of nitazoxanide in adults and adolescents with acute uncomplicated influenza: a double-blind, randomised, placebo-controlled, phase $2 \mathrm{~b} / 3$ trial. Lancet Infect Dis. 2014;14(7):609-618. doi: 10.1016/s1473-3099(14)70717-0. [published Online First: 2014/05/24] [PMC free article] [PubMed] [CrossRef] [Google Scholar]

48. Santulli G. MD (2015). Adrenal Glands: From Pathophysiology to Clinical Evidence. Nova Science Publishers, New York, NY. ISBN 978-1-63483-570-1.

49. Jefferies, William McK (2004). Safe uses of cortisol. Springfield, Ill: Charles C. Thomas. ISBN 978-0-398-075002.

50. O'Hare, A. Munro Neville, Michael J. (1982). The Human Adrenal Cortex Pathology and Biology - An Integrated Approach. Springer London. pp. Chapter 4: Structure of the adult cortex. ISBN 978144711317

51. Whitehead, Saffron A.; Nussey, Stephen (2001). Endocrinology: an integrated approach. Oxford: BIOS. p. 122. ISBN 978-1-85996-252-7.

52. Rossignol. J. F. and H. Malsonneuve (1984). "Nitazoxanide in the treatment of Taenia saginata and Hymenolepis nana infections.” Am J Trop Med Hyg 33 (Copyright (C) 2015 U.S. National Library of Medicine): 511-512.

53. Hench PS, Kendall EC, Slocumb CH, et al. The effect of a hormone of the adrenal cortex (17-hydroxy-11dehydrocorticosterone; compound E) and of pituitary adrenocorticotropic hormone on rheumatoid arthritis. Mayo Clin Proc. 1949;24:181-197. 2.

54. Hench PS, Kendall EC, Slocumb CH, et al. Effects of cortisone acetate and pituitary ACTH on rheumatoid arthritis, rheumatic fever, and certain other conditions. Arch Intern Med (Chic). 1950;85:545-666.

55. Ericson-Neilsen W, Kaye AD. Steroids: pharmacology, complications, and practice delivery issues. Ochsner J. 2014;14:203-207.

56. Van der Goes M, Jacobs JW, Bijlsma JW. The value of glucocorticoid co-therapy in different rheumatic diseasespositive and adverse effects. Arthritis Res Ther. 2014;16 Suppl 2:S2.

57. Weinstein RS. Glucocorticoid-induced osteoporosis and osteonecrosis. Endocrinol Metab Clin North Am. 2012;41:595611.

58. Cosman F, de Beur SJ, LeBoff MS, et al. Clinician's guide to prevention and treatment of osteoporosis. Osteoporos Int. 2014;25:2359-2381.

59. American College of Rheumatology. Recommendations for the prevention and treatment of glucocorticoidinduced osteoporosis: 2001 update. Arthritis Rheum. 2001;44:14961503. 
60. Schakman O, Gilson H, Thissen JP. Mechanisms of glucocorticoid-induced myopathy. J Endocrinol. 2008;197:110.

61. Da Silva JA, Jacobs JW, Kirwan JR, et al. Safety of low dose glucocorticoid treatment in rheumatoid arthritis: published evidence and prospective trial data. Ann Rheum Dis. 2006;65:285-293.

62. McGavock JM, Lingvay I, Zib I, et al. Cardiac steatosis in diabetes mellitus: a 1H-magnetic resonance spectroscopy study. Circulation. 2007;116:1170-1175.

63. Van der Hooft CS, Heeringa J, Brusselle GG, et al. Corticosteroids and the risk of atrial fibrillation. Arch Intern Med. 2006;166:1016-1020.

64. Souverein PC, Berard A, Van Staa TP, et al. Use of oral glucocorticoids and risk of cardiovascular and cerebrovascular disease in a population based case-control study. Heart. 2004;90:859-865.

65. Huscher D, Thiele K, Gromnica-Ihle E, et al. Dose-related patterns of glucocorticoid-induced side effects. Ann Rheum Dis. 2009;68:1119-1124.

66. Aceto T, Beckhorn GD, Jorgensen JR, et al. Iatrogenic ACTHcortisol insufficiency. Pediatr Clin North Am. 1966;13:543557.
67. Brown ES, Chandler PA. Mood and cognitive changes during systemic corticosteroid therapy. Prim Care Companion J Clin Psychiatry. 2001;3:17-21.

68. Fel A, Aslangul E, Le Jeunne C. [Eye and corticosteroid's use]. Presse Med. 2012;41:414-421.

69. James ER. The etiology of steroid cataract. J Ocul Pharmacol Ther. 2007;23:403-420

70. Czock D, Keller F, Rasche FM, H€aussler U. Pharmacokinetics and pharmacodynamics of systemically administered glucocorticoids. Clin Pharmacokinet. 2005;44:61-98.

71. Tanaka H, Hirano F, Nomura Y, et al. Relative glucocorticoid potency revisited. Rheumatol Int. 1994;14:9-12

72. D. Mosholder, J. Mathew, J. J. Alexander, H. Smith, and S. Nambiar, "Cardiovascular risks with azithromycin and other antibacterial drugs," The New England Journal of Medicine, vol. 368, no. 18, pp. 1665-1668, 2013.View at: Publisher Site | Google Scholar

73. Mandeep R, Mehra, Sapan S Desai, Frank Ruschitzka, Amit N Patel. Hydroxychloroquine or chloroquine with or without a macrolide for treatment of COVID-19: a multinational registry analysis. May 22, 2020 https://doi.org/10.1016/S01406736(20)31180-6.

74. BMJ 2020;369:m2422 http://dx.doi.org/10.1136/bmj.m2422 Published: 16 June 2020

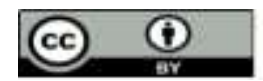

This work is licensed under Creative Commons Attribution 4.0 License
To Submit Your Article Click Here: Submit Manuscript

DOI: $10.31579 / 2641-0419 / 200$
Ready to submit your research? Choose Auctores and benefit from:

* fast, convenient online submission

* rigorous peer review by experienced research in your field

* rapid publication on acceptance

* authors retain copyrights

* unique DOI for all articles

* immediate, unrestricted online access

At Auctores, research is always in progress.

Learn more auctoresonline.org/journals/journal-of-surgical-case-reportsand-images 
